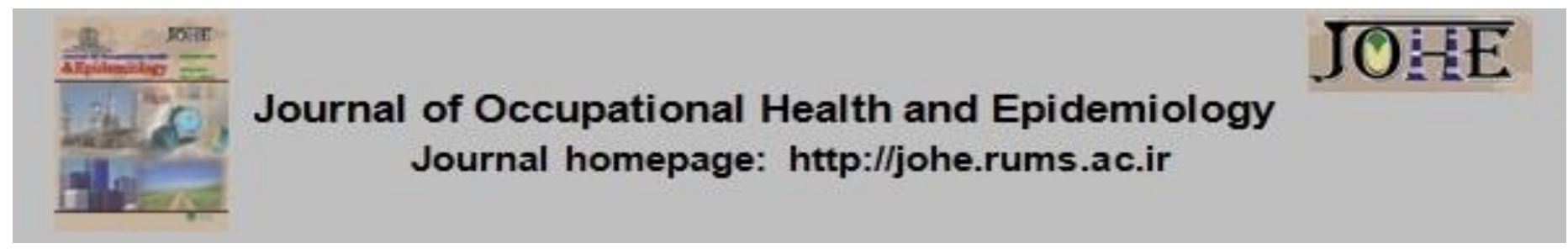

\title{
Investigating the Adequacy of Nurses' Training based on a Hybrid Approach
}

\author{
Banafsheh Shafei ${ }^{1}$, Maryam Sameri ${ }^{*}$ \\ 1. PhD in Educational Administration, Dept. of Education, Urmia Branch, Islamic Azad University, Urmia, Iran; Management of Social \\ Security Treatment in West Azarbaijan Province, Urmia, Iran. \\ 2. PhD in Educational Administration, Dept. of Education, Urmia Branch, Islamic Azad University, Urmia, Iran.
}

Citation: Shafei B, Sameri M. Investigating the Adequacy of Nurses' Training based on a

Hybrid Approach. JOHE 2021; 10(1):39-47.

\section{Article Info}

* Corresponding author:

Maryam Sameri,

E-mail:

m.sameri@iaurmia.ac.ir

\section{Article history}

Received: Dec 2020

Accepted: Mar 2021

10.29252/johe.10.1.39

Print ISSN: 2251-8096 Online ISSN: 2252-0902

Peer review under responsibility of Journal of Occupational Health and Epidemiology

\begin{abstract}
Background: In the present era, training is one of the most complex tasks in the human resource management of organizations and also one of the factors in organizational productivity. This study was conducted to identify the dimensions and components of adequate training of nurses with an emphasis on psychological empowerment.

Materials and Methods: The present study is quantitative and qualitative research with a descriptive-exploratory design, and in terms of purpose, it is applied research. In the qualitative approach, to collect the necessary data, in-depth interviews were done. The sample included 30 cases consisting of university faculty members and senior managers of nurses. In the quantitative approach, 200 nurses were selected by simple random sampling. To analyze the data, Strauss and Corbin (1990) approach and fuzzy Delphi technique have been used.

Results: Based on the findings, the main components of the adequacy of nurses' education include training, evaluation and psychological empowerment. The results showed that, among these three dimensions, the largest gap for optimizing the model was related to the psychological empowerment dimension, which can be filled by focusing on the sense of competence, sense of significance and sense of effectiveness of nurses.

Conclusion: The results showed that psychological empowerment by creating a sense of competence, meaningfulness, and effectiveness led to the participation of nurses in the training courses voluntarily and without coercion because they felt they needed to know more, and by psychological empowerment, they will be able to achieve the adequacy of training.
\end{abstract}

Keywords: Training, Nurse, Empowerment, Psychological

\section{Introduction}

The importance of effective and focused training for employee development in today's competitive markets is inevitable [1]. In healthcare organizations, knowledgeable and efficient human resources are considered as key elements of effectiveness and productivity. The basic step in training and retraining useful and efficient workforce is the ability of an organization to properly and adequately educate employees and managers. Although in many countries, the Ministry of Health is more or less concerned with the training of the workforce in the health sector, its direct involvement in maintaining patients' health and life, and its decisive role in improving the quality of services and increasing productivity, the training and retraining of the workforce in the healthcare sector should not be overlooked [2]. Fitzsimons (2017) argues that intelligent and experienced human capital in healthcare systems is considered a source of competitive advantage [3]. In healthcare systems, due to the important role of nurses in improving health standards, it is crucially important to update training, and 
theoretical and practical knowledge, as well as training methods for this group of medical staff. Adequate and appropriate training of nurses is essential to provide efficient and effective services and to achieve patient satisfaction. In their studies, the researchers have emphasized a direct and significant relationship between nurses' training and their performance and considered their lack of adequate training as a weakness in providing healthcare services [4]. Continuous and adequate training and improvement of nursing staff in healthcare organizations can be used as a useful method in maintaining professional skills and preventing their stagnation, as well as improving their job abilities. Therefore, currently, paying enough attention to this factor is one of the most important tasks of managers [5]. Adequacy of training is the acquisition of the necessary competence to perform obligations and duties through training. Thus, adequacy means acquiring the necessary competence, that is to say, one can achieve the necessary competence through training. Unfortunately, only about $6 \%$ of organizations base their training plans on the real needs and training adequacy of employees [6]. The effectiveness of education is the fruit of adequate and appropriate training, which is tailored to the needs of individuals and can be referred to as the adequacy of training. This type of training not only improves an individual's overall performance but also ultimately improves organizational performance and effectiveness. Senge [7], a well-known expert in the field of human resource management, considers personnel training to include four stages: needs assessment, design, learning method selection, and evaluation of learning outcomes [8]. The training and improvement of personnel in the DDE (Design, Development and Evaluation) model proposed by Garavan, Hogan, and Donnell has several distinctive features. First, in this process, the focus of attention is on contextual factors in planning personnel training. Second, employees' growth opportunities, too, has been considered as a needs assessment factor, and third, special emphasis has been placed on the use of managers and supervisors as course instructors. Finally, the calculation of the rate of Return on Investment (ROI) has been considered and emphasized. In general, it can be said that the main focus of all these training processes is the three elements of planning, implementation and evaluation [9].

In the human development, the expansion of the necessary facilities such as training to make use of (the employees') talents, and the development of capabilities are regarded as components of development. From this perspective, achieving the necessary level of development and adequacy includes both instrumental and non-instrumental concepts at the same time, emphasizing that achieving the necessary educational adequacy, in addition to tools and instruments, requires attention to psychological issues such as motivation building, self-esteem, etc. [7]. Training adequacy enhances effectiveness by paying attention to psychological aspects. Dehghani et al. [10], Awadh, and Ismail [11], Ateya, Maende [12], and Hammond \& Churchill also obtained similar results. [13] .Healthcare organizations have undergone many changes in terms of science and technology or the use of new methods, but unfortunately, neither the efficiency nor quality of services of these organizations has improved as expected. One of the reasons for this is that in these changes, effective training and adequacy of training of employees have not received enough attention by these systems. It seems that most of the reasons for the failure of nurses' training programs are related to lack of adequacy of training. Human resource thinkers believe that leading organizations can meet business needs with greater speed and flexibility only by using advanced and scientific models of human resource training and development, organizational learning, and strategies for the development of employees' capabilities.

This study aims at presenting the adequacy model of training of nurses at Imam Reza Hospital affiliated to the Social Security Organization. Hence, based on different perspectives, three dimensions of training, psychological empowerment and training evaluation have been identified as indicators and factors of adequacy of training of nurses. It is clear that the composition of these factors in different organizations varies depending on their needs.

In this study, some managerial orientations in the field of adequacy of training in Iran's 1404 Vision Policy (2025-2026) and the general policies of the government within the vision's period, the law of the Fourth Economic, Social, and Cultural Development Plan of the Islamic Republic of Iran, the Fifth Development Law, the general policies of the state administrative system (2010) have also been examined. In designing the present model, an attempt has been made to pay attention to the ecological approach to the adequacy of training of Social Security nurses due to the problems of training of nurses in healthcare systems. Because without deep knowledge about the political, social, cultural and economic characteristics of the country, no universal decision can be made in terms of adequacy of training $[14,15]$. 
Emphasizing the effectiveness of the adequacy of training and being based on the ecological approach to the adequacy of training, the present study is similar to the research by Deitmor [16] and Eidi et al. [17] in this respect. By studying the theoretical foundations and seeking the opinion of supervisor professors and experts, the research framework is based on Garavan, Hogan and Donnell's model [18] (2007). On this basis, the adequacy of training model consists of three dimensions of training, psychological empowerment and Training evaluation. Garavan, Hogan and Donnell's model [18] (2007) provides a more comprehensive picture of training than other models. Therefore, in designing the conceptual model of the research, the structures of the model are based on studying the theoretical foundations and validation thereof by experts according to Phillips model. In addition, the components of the structures have been identified by studying the research literature and conducting in-depth interviews with experts (senior managers, training officials, supervisors and nurses affiliated to the Social Security Organization) as well as two phases of the fuzzy Delphi method.

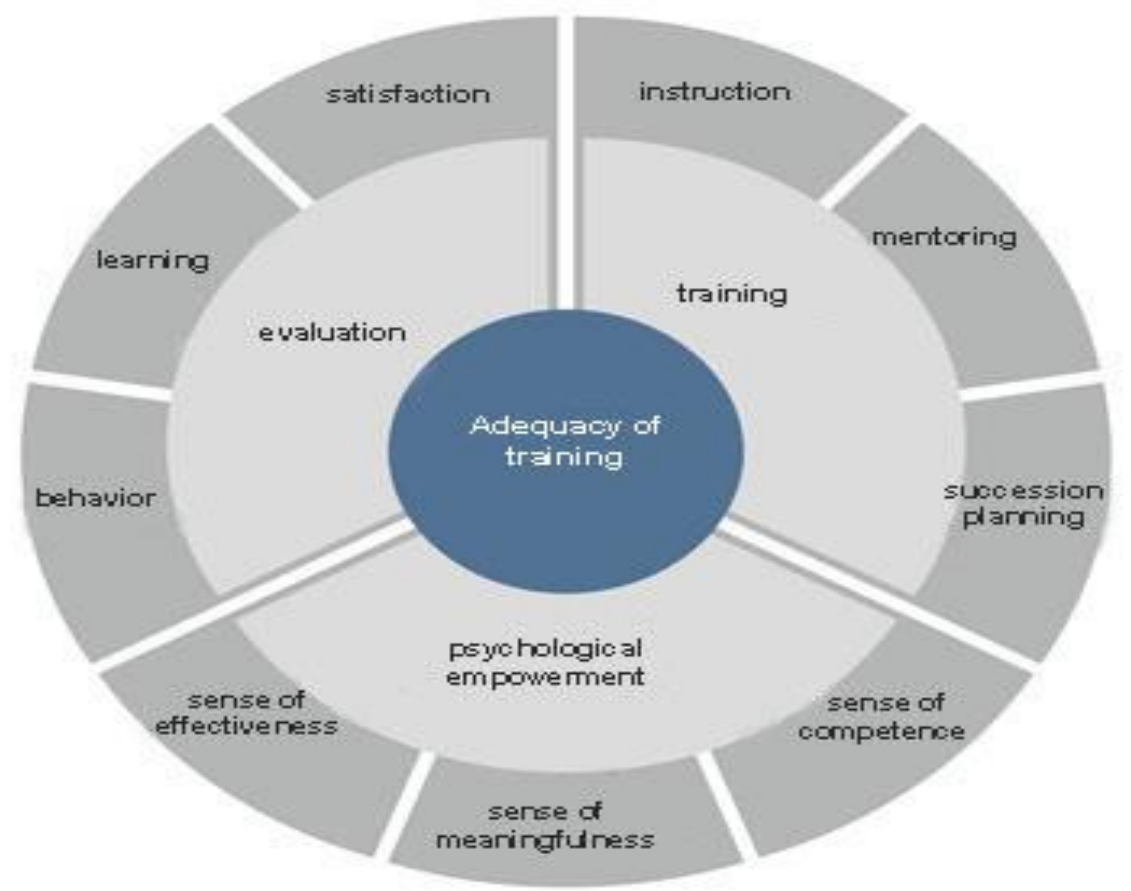

Fig. 1. Conceptual model of the research

\section{Materials and Methods}

In terms of the purpose of study, this is applied research and in terms of nature, it is a descriptivesurvey study. In terms of methodology of research, a triangulated approach (quantitative and qualitative) is adopted. It is quantitative since the concepts proposed by Garavan, Hogan and Donnell [18] (2007) are tested at Imam Reza Hospital in Urmia in 2020; it is qualitative since indepth interviews are used to acquire the necessary information regarding the dimensions of adequacy of training. Strauss and Corbin (1990) approach and fuzzy Delphi technique [19] have been used to analyze the data. In-depth interviews were conducted with the statistical sample including experts experienced in management and training in the Social Security Organization and university professors. The inclusion criteria were the cases' familiarity with and expertise in the field of nursing, training and management at Imam Reza Hospital in Urmia, who were selected through snowball sampling method. Sample members for collecting the necessary information through in-depth interviews included 30 cases consisting of university professors, senior managers of nurses. No new information was obtained from the 22nd interview on, but the interviews continued until the 30th case to make sure there were no new results. Each interview began with questions in the form of an open interview about the components of each of the dimensions of adequacy of training. The main question was "How do you think the training adequacy of nurses is achieved?" The rest of the questions were asked based on the interviewee's answers, that is, they were mostly contextual and adjusted to the respondent's answers. The Strauss and Corbin [20] approach (1990) was used to analyze qualitative data in three stages of open, central, and selective coding. After analyzing the interviews, in the first stage, open coding was applied on them and each component related to the research question was assigned a label of words. This was repeated for each of the twentyseven interviews, and by placing similar codes next to each other, classes, features, and dimensions were provided for central coding. At this stage, concepts that are more abstract were 
used for better classification and coverage of similar codes.

Next, in order to complete the conceptual model, in addition to the theoretical foundations of the research, the fuzzy Delphi technique was employed with the following steps: definition of linguistic variables, first-stage survey, secondstage survey, third-stage survey. The panel members included senior managers, training officials, nursing officials and experienced nurses at Imam Reza Hospital, numbering 30 people. The inclusion criteria were expertise in the field of healthcare and nursing jobs and members' experience in the field of training and academic studies in the field of educational management, having experience in the field of staff training and work experience in the field of nursing management and nursing. The exclusion criteria were unwillingness to participate, lack of experience and information in the field of staff training. These members were selected based on purposeful sampling for completing the questionnaires. The questionnaires were sent in person, or via e-mail and Telegram cyberspace. It should be noted that the return rate of the questionnaires was $75 \%$ that is out of 30 questionnaires, a total of 22 questionnaires were collected and the work continued into the second stage with these 22 questionnaires to analyze the results. As mentioned above, the initial research model was based on Garavan, Hogan and Donnell's model [18] (2007). This model is only a presentation of the concepts related to the adequacy of training and does not have the required power to develop a theory. Therefore, it is attempted to introduce the conceptual model presented with the help of exploratory studies, indepth interviews and panel formation and, in this way, identify and count the components related to each dimension and implement the designed model in Social Security health centers. Therefore, the nurses at Imam Reza Hospital were selected as the statistical population to complete the questionnaires and a simple random sampling method was used for sampling. In this study, the ethical considerations, including full assurance of confidentiality of information and freedom of participation in interview sessions or leaving them, as well as the optional completion of questionnaires at each stage of the research were taken into account.

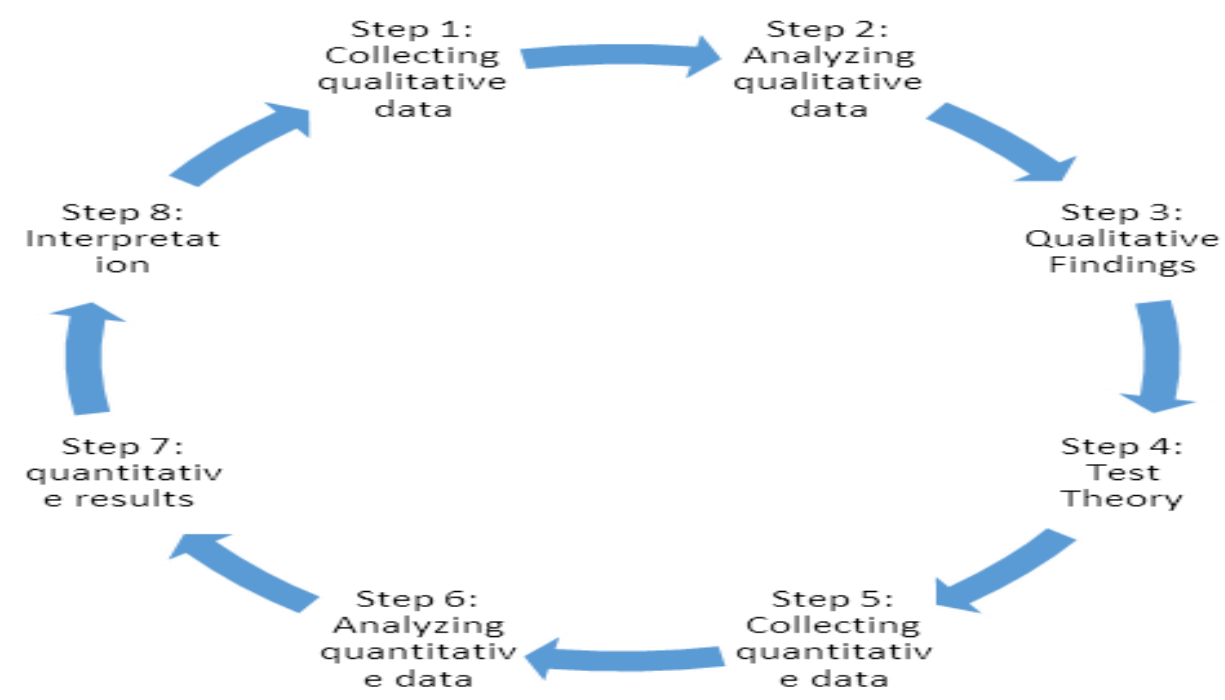

Fig. 2. Exploratory Approach to the Research Process (Creswell (20), 2005)

\section{Results}

Exploratory studies with the process of fuzzy Delphi technique were performed in three stages as follows to achieve the components of the research: The first step was to define linguistic variables. In this regard, the panel members expressed their agreement with the 21-component model of adequacy of training through verbal variables including very low, low, medium, high and very high. Since different characteristics of individuals affect their mental interpretations of qualitative variables, defining the range of qualitative variables helped experts answer the questions with the same mindset. In the following step, the expert panel was needed (Table 2).

Table 2. Research Expert Panel Members

\begin{tabular}{cc}
\hline Members & Number \\
\hline Senior managers & 2 \\
\hline Training director & 2 \\
\hline Supervisor \& head nurse & 8 \\
\hline Expert nurses & 16 \\
\hline University professors & 2 \\
\hline Sum & 30 \\
\hline
\end{tabular}




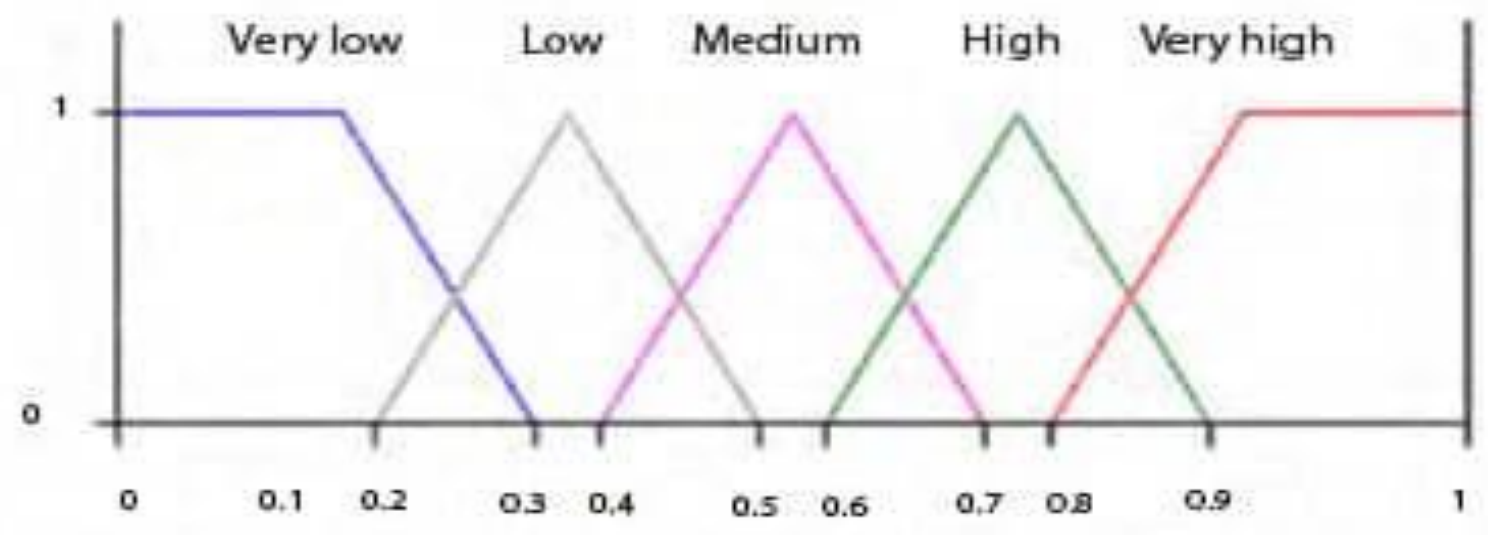

Fig. 3. Linguistic Variables

These variables are defined in the form of triangular fuzzy numbers according to Table 3 and Fig. 3.

Table 3. Triangular Fuzzy Numbers of Verbal Variables

\begin{tabular}{ccc}
\hline $\begin{array}{c}\text { Verbal } \\
\text { variables }\end{array}$ & $\begin{array}{c}\text { Triangular } \\
\text { fuzzy number }\end{array}$ & $\begin{array}{c}\text { Finalized } \\
\text { fuzzy number }\end{array}$ \\
\hline Very high & $(1,0 / 25,0)$ & $0 / 934$ \\
\hline High & $(0 / 75,0 / 15,0 / 15)$ & $0 / 71$ \\
\hline Medium & $(0 / 5,0 / 5,0 / 5)$ & $0 / 5$ \\
\hline Low & $(0 / 25,0 / 25,0 / 25)$ & $0 / 29$ \\
\hline Very low & $(0,0,0 / 25)$ & $0 / 11$ \\
\hline
\end{tabular}

In the second phase, the first stage of the survey was conducted in which the 21-component conceptual model was delivered in full to the panel members and their opinions about the model were elicited. The answers to the questions were calculated by means of a triangular fuzzy mean and then defuzzified using the Minkowski formula. The final mean obtained was considered as the strength of the panel members' agreement with each of the components of the conceptual model. Considering that in addition to the close-ended questions, the experts' views were also taken into account in the questionnaire, the supervisor and the reader's opinions were also elicited, and after corrective measures, the second stage of the survey began. At this stage, the second questionnaire was prepared and sent to the panel members, along with each person's previous point of view and the extent of the differences between their viewpoints with those of other experts. Panel members answered the questions again based on the views of other members and the changes made. At this stage, the same steps as the previous stage were taken and the results were collected. Comparing the views presented in the first and second stages demonstrated that the difference between the two stages for 21 components is much lower than the threshold of "very low", that is, $(0.1)$, so the survey process was stopped for the second stage and out of 21 components submitted to members, the 9component panel was approved. In the third stage, based on the deleted components, the concept model was designed with 9 components and sent back to the panel members. At this stage, it was observed that the difference of opinions of experts in the second and third stages was very low (0.1). Therefore, the survey was stopped at this stage, too.

Then, the hierarchical cluster analysis technique was used to cluster cultural barriers to adequately training of hospital nurses. In clustering, an inhomogeneous group is divided into several homogeneous subgroups. Therefore, the hierarchical clustering method can be used, which is one of the most widely used cluster analysis methods. Therefore, first, using a criterion, the distances of subgroups were defined and then the Euclidean distance criterion was used to form the clusters and link them together. In applying the Euclidean distance, when two or more variables are used to determine the distance, an attempt is made to dominate the variable that is the most important. Therefore, at this stage, all variables were standardized to prevent problems. The clustering results are shown in Table 4. 
Table 4. Clustering program in hierarchical clustering

\begin{tabular}{|c|c|c|c|c|c|c|}
\hline \multirow[t]{2}{*}{ Stage } & \multicolumn{2}{|c|}{ Cluster composition } & \multirow[t]{2}{*}{ coefficients } & \multicolumn{2}{|c|}{$\begin{array}{c}\text { Cluster formation for } \\
\text { the first time }\end{array}$} & \multirow{2}{*}{$\begin{array}{l}\text { Next } \\
\text { stage }\end{array}$} \\
\hline & Cluster 1 & Cluster 2 & & Cluster 1 & Cluster 2 & \\
\hline$\cdot$ & $\cdot$ & $\cdot$ & $\cdot$ & $\cdot$ & $\cdot$ & \\
\hline$\cdot$ & $\cdot$ & $\cdot$ & $\cdot$ & $\cdot$ & $\cdot$ & \\
\hline . & . & . & . & . & . & . \\
\hline 203 & 20 & 11 & 0.365 & 199 & 0 & 201 \\
\hline 204 & 7 & 4 & 0.765 & 0 & 0 & 203 \\
\hline 205 & 5 & 7 & 0.645 & 195 & 200 & 205 \\
\hline 206 & 5 & 39 & 1.22 & 200 & 201 & 207 \\
\hline \multirow[t]{4}{*}{207} & 6 & 16 & 0.676 & 0 & 0 & 205 \\
\hline & $\cdot$ & $\cdot$ & $\cdot$ & $\cdot$ & $\cdot$ & $\cdot$ \\
\hline & $\cdot$ & $\cdot$ & $\cdot$ & $\cdot$ & $\cdot$ & $\cdot$ \\
\hline & . & . & . & . & . & . \\
\hline 209 & 3 & 4 & 13.187 & 0 & 208 & 0 \\
\hline
\end{tabular}

In the following, based on the clustering obtained, and using mathematical function, we seek to achieve the optimal triangulation of training, psychological empowerment and evaluation regarding the adequacy of training of nurses at Imam Reza Hospital. For this purpose, assuming that the relationship is linear and using Zelen's design, various behaviors have been investigated to achieve greater effectiveness in training. Effectiveness is defined within a 0-1 range, and each time it is solved as to the amount of 0.01 to select the optimal answer for the adequacy of the training. The general renewable model in the present study is as follows:

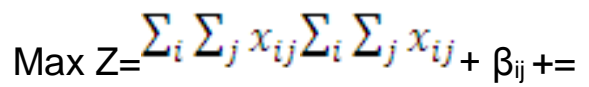

$\sum_{j} \Sigma_{k} y_{j k} \Sigma_{j} \Sigma_{k} y_{j k} \beta_{j k}^{\circ} \beta_{j k}^{\circ}$

$$
\begin{aligned}
& \text { s. to: } \\
& \sum_{j=1}^{3} y_{j k} \sum_{j=1}^{3} y_{j k} \geq \mathrm{CT}_{\mathrm{k}} \quad \mathrm{V}_{\mathrm{k}} \\
& \sum_{i=a}^{l} x_{i j} \sum_{i=a}^{l} x_{i j} \geq \mathrm{Bet}_{\mathrm{j}} \quad \mathrm{V}_{\mathrm{j}} \\
& \sum_{i=a}^{l} x_{i j} \sum_{i=a}^{l} x_{i j} \geq \sum_{j=1}^{3} y_{j k} \sum_{j=1}^{3} y_{j k} \quad \mathrm{~V}_{\mathrm{j}} \\
& \mathrm{X}_{\mathrm{ij}, \mathrm{y}_{\mathrm{jk}} \geq 0}
\end{aligned}
$$

In the above relation, xij and yjk are the values of each variable, $Z$ is the obtained benefit, $\beta \mathrm{ij}$ and $\beta_{j k}^{\delta} \beta_{j k}^{\delta}$ are the profit from the production of one unit of each variable, Betj is the coefficient of the obtained variables, CTk is the coefficient of the adequacy of training for this system. The results are presented in Table 5 with the assumption of three clusters and three variables for the status quo.

Table 5. Investigating the amount of research variables in the status quo and the desired status and gap diagnosis

\begin{tabular}{ccccccc}
\hline & Low limit & Current limit & Desired limit & High limit & Margin & Gap \\
\hline VAR z & - INF & $41 / 0$ & 1 & + INF &. & \\
\hline Training & - INF & $0 / 13$ & $0 / 15$ & + INF & EPS & $+0 / 02$ \\
\hline Empowerment psychological & - INF & $0 / 17$ & $0 / 31$ & + INF & EPS & $+0 / 14$ \\
\hline Evaluation & - INF & $0 / 25$ & $0 / 31$ & + INF & EPS & $+0 / 06$ \\
\hline
\end{tabular}

The findings of this study show that there are several contributing factors in the realization of the adequacy of training of nurses, such as 1) Psychological empowerment with the components of creating a sense of competence, meaningfulness and effectiveness; 2) Evaluation with the components of needs assessment and evaluation of courses; 3) Training with instruction, mentoring and successor planning components. However, based on the findings, among all factors, the role of the psychological empowerment component with a gap of 0.14 , that is the maximum gap to achieve adequacy of training of nurses, was very important and necessary. In other words, the adequacy of training of the nurses is accompanied by continuous development and learning, and its role is very important in improving and enhancing the knowledge, skills, attitudes and behaviors of employees to perform specific organizational tasks. In general, based on the results of this study, it can be concluded that the training of nurses, along with psychological empowerment by creating a sense of competence, effectiveness, and meaningfulness in individuals, will help the realization of the goals 
of training courses and their higher level of effectiveness. Because it is under these circumstances that learning and training will lead to the improvement of individuals and employees will be constantly striving to learn. In this situation, employees know why and how to learn and take responsibility for their own learning, and they will not even wait for the organization to plan the training for them. Rather, they will eagerly pursue learning and developing their knowledge and skills. In other words, without psychological empowerment and motivation building in individuals to participate in education and learning, the results of large investments in training will be limited to the implementation of guidelines for organizational tasks and will not have significant outcomes other than the loss of huge costs and even employee boredom and discouragement. Moreover, no result will be achieved except for the physical presence of people in the sessions and minor changes in their level of knowledge, and much of the material and many skills learned will be buried there with the end of the course and will not have the necessary effect and satisfy the expectations. Therefore, an essential strategy to improve and develop an organization's human resources, especially nurses, is that it pays special attention to the adequacy of training and important contributing factors. Based on the model explained in the adequacy of training for nurses, the psychological empowerment dimension showed a larger gap of 0.14 , compared to the other two dimensions, which has the highest value among other dimensions and shows how much this factor is important for the organization in terms of the adequacy of training. To address the existing gap and increase the effectiveness of training, the healthcare organizations are required to focus more on psychological empowerment. This increase will occur with the priority given to the weight and the role of psychological empowerment by creating a sense of competence, a sense of meaningfulness and a sense of effectiveness among employees. Ditmore SW (24) (2007) believes that the psychological empowerment dimension is much more important than other dimensions in employee training.

\section{Discussion}

Today's environments are very dynamic, so to adapt to this dynamism and change, increasing power, skills, understanding new environments, awareness of modern knowledge, science and technology, certainly requires systematic, correct, adequate and continuous training. Considering the fact that various internal and external factors can affect the adequacy of training, a number of these factors were discussed in this study due to the great importance of the proposed features and their impact on the effectiveness of training. Despite the importance of psychological empowerment in the adequacy of training, it should be noted that moving from the status quo to the desired training status in healthcare systems requires a lot of attention to the new composition proposed. That is, according to some management scholars such as Benar, Loghmani [21], the combination of the roles of all three factors of training, psychological empowerment and training evaluation should be considered in achieving the intended goal.

Based on the results of this study, 9 components have been identified which are involved in the adequacy of training of nursing staff in the form of 3 categories of factors. In order to achieve higher effectiveness, it is necessary to pay attention to the compatibility between these factors and their subcomponents so that it can be useful for the adequacy of nurses' training in the long run. Training, instruction, mentoring and succession are regarded as the factors affecting the adequacy of training, which according to the results of this study, with a gap of 0.02 had a smaller gap than other factors. Paying attention to the type of training provided by trainers and supervisors or the people with special knowledge and skills, and transferring this knowledge and skills to other members through instruction, mentoring or succession training can increase the organization's performance and effectiveness. Of course, this is not a simple task and requires the right choice of tools and techniques to be used in a coordinated manner. In order to choose the right type of tool, it is necessary to understand the existing legal and cultural infrastructures, jobs and careers in an organization. Furthermore, it is important to understand how to combine these components to achieve the adequacy of training. In addition to the training dimension, what adequacy of training requires is the training evaluation.

Based on the results, this dimension shows a gap of 0.06 . Evaluation plays an important role in the necessary steps from the beginning to the end of the training process. Training evaluation results can be considered the best input in future training planning. Ibrahim et al. (2013) show that the issues related to the evaluation dimension can be established and extended in all adequacy of training processes. However, the adequacy of training will manifest its main function by having a special order in the implementation of training steps, and inconsistency in the implementation of this process can reduce the effectiveness of other 
steps. In this dimension, it was found that there is a gap of 0.06 , and that new scientific and up-todate methods of training evaluation, which are congruous with the local and cultural factors should be employed, taking into account needs assessment, course holding and evaluation.

It is suggested that hospital managers focus on psychological empowerment in order to provide nursing staff with adequate training, while improving the quality of service delivery, and improving individual and organizational performance to make the organization more effective and ultimately increase the public health of the community. This means that in the psychological dimension, by creating competence, significance and effectiveness, nurses participate in training voluntarily and without coercion due to the need to acquire more knowledge and skills.

\section{Conclusion}

This study showed that by empowering employees, the individuals, themselves, seek the necessary training to become more capable and develop their skills, and always strive to provide the necessary training platforms by motivating themselves and others. In fact, the most important advantage of this dimension over other dimensions is that in the other two dimensions, training is mandatory and of task-fulfillment nature; however, in the psychological dimension, there is no force and the individuals voluntarily attend the training sessions for the need to know and learn more become more skillful, which will automatically put them on the path to the adequacy of training.

\section{Acknowledgement}

This article is part of the doctoral dissertation of the Educational Management at the Islamic Azad University, Urmia Branch, with the code of ethics IR.IAU.URMIA.REC.1398.026, which has been registered by the National Ethics Committee of the Islamic Azad University, Urmia Branch. Hereby, the efforts of the esteemed Vice-Chancellor for Research \& Technology at Urmia Islamic Azad University, the General Directorate of Education and Research, the officials and nurses of Imam Reza Hospital in Urmia are appreciated.

Conflict of interest: None declared.

\section{References}

1. Adekoya OD, Jimoh I, Okorie G, Olajide M. Significance of Employee Engagement and Individual Well-Being on Organisational
Performance in Nigeria. International Journal of Science and Management Studies 2019; 2(5):35-47.

2. Shabani Bahar GR, Farid Fathi A. Role of University Education in Developing Productivity of Employees of Ministry of Sport and Youth. Journal of Human Resource Management in Sport 2018; 5(2):277-90.

3. Ashour AM, Hassan Z, Alekam JME. A Conceptual Framework for Upgrading Safety Performance by Influence Safety Training, Management Commitment to Safety and Work Environment: Jordanian Hospitals. International Journal of Business and Social Research 2018; 8(7):25-35.

4. Zahoor H, Muhammad G, Ali M. Impact of Training and Development on Nursing and Technical Staffs' Performance and Motivation: A case of secondary health care sector at Shamsi hospital Karachi. In: Kürşat Cross, Editor. Conference Book Proceedings of the 2nd InTraders International Conference on International Trade; 2018; Istanbul, Turkey. Istanbul: Hyperlink Publications, 2018.

5. Mohammadi MA, Dadkhah B. Continuous Medical Education from View of Nursing Personnel Working in Ardabil Hospitals. Journal of Ardabil University of Medical Sciences 2005; 5(3):271-7.

6. Alibaba Govarrchin Qala E. The Effect of Technical and Vocational Training on Job Motivation and Job Commitment of Students of Urmia Regional Technical and Vocational Organization with the Mediating Role of Education Adequacy and Self-Sufficiency. [MSc Thesis]. Urmia, Iran: Urmia Branch, Islamic Azad University; 2017.

7. Fanikhayavi R, Mardani N, Mardani S. Analysis of Peter Senge'S Five Commandments Learning in Organizations and Adherence Tot The Islamic Azad University Staff of Its Components. CES Working Papers 2014; 6(1):77-86.

8. Faraji R, Hesami SK, Haghdoost R. A Comparative Study of Organizational Training Models and Introducing ISO 10015 Comprehensive Training System. Standard and Quality Management Journal 2015; 5(1):45-54.

9. Toosi MA, Saebi M. Personnel - Human Resource Management [RS. Schuler, SL. Dolan Trans]. Tehran: Management Training Center Publication; 2011.

10. Dehghani A, Daghighi Asli A, Pourvali F. The Effect of In-Service Training on Competencies and Occupational Performance of Employees in an Insurance Company. Iranian Journal of Insurance Research 2015; 30(118):35-60

11. Awadh AM, Wan Ismail WK. The Impact of Personality Traits and Employee Work-Related Attitudes on Employee Performance with the Moderating Effect of Organizational Culture: The Case of Saudi Arabia. Asian Journal of 
Business and Management Sciences 2012; 1(10):108-27.

12. Wesonga LA. Employee Training and Performance of Programme for Agriculture and Livelihoods in Busia County, Kenya. [MSc thesis]. Kahawa, Nairobi County, Kenya: Kenyatta University; 2018.

13. Hammond $H$, Churchill RQ. The Role of Employee Training and Development in Achieving Organizational Objectives: A Study of Accra Technical University. Archives of Business Research 2018; 6(2):67-74.

14. Wilson JP. Human Resource Development: Learning \& Training for Individuals \& Organizations. 2nd ed. London, United Kingdom: Kogan Page; 2005.

15. Owan H. Promotion, Turnover, Earnings, and Firm-Sponsored Training. Journal of Labor Economics 2004; 22(4):955-78.

16. Dittmore SW. Examining Fairness Perceptions of Financial Resource Allocations in U.S. Olympic Sport. [Phd thesis]. Louisville,
Kentucky, United States: University of Louisville; 2007.

17. Heady F. Public Administration, A Comparative Perspective. 6th ed. London, United Kingdom: Routledge; 2001.

18. Garavan TN, Hogan C, Cahir-O'Donnell A. Developing Managers and Leaders: Perspectives, debates and practices in Ireland. 1st ed. Dublin, Ireland: Gill \& Macmillan; 2009.

19. Strauss A, Corbin J. Grounded Theory in Practice. 1st ed. Thousand Oaks, California, United States: SAGE Publications, Inc; 1997.

20. Creswell JW. Educational Research: Planning, Conducting, and Evaluating Quantitative and Qualitative Research. 1st ed. Hoboken, New Jersey, United States: Prentice Hall; 2001.

21. Benar N, Loghmani $M$. The relationship between goal-orientations and sport commitment among athletes. Pedagogics, Psychology, Medical-Biological Problems of Physical Training and Sports 2012; 5:154-60. 